\title{
Silver-Russell syndrome due to maternal uniparental disomy of chromosome 7
}

INSERM

\section{Source}

INSERM. (1999). Orphanet: an online rare disease and orphan drug data base. SilverRussell syndrome due to maternal uniparental disomy of chromosome 7. ORPHA:96182

Silver-Russell syndrome due to maternal uniparental disomy of chromosome 7 is a genetic malformation syndrome with short stature characterized by severe prenatal and postnatal growth retardation, feeding difficulties, body asymmetry, dysmorphic craniofacial features (triangular-shaped face, relative macrocephaly, frontal bossing, microg nathia, down-turned corners of the mouth) and other anomalies (fifth finger clinodactyly, café au lait macules, male genital anomalies, mild developmental delay and/or speech delay with movement disorders). 